\title{
Fecundidad y comportamiento reproductivo en la sierra y selva del Perú
}

\author{
Alfredo L. Fort*
}

El artícuio intenta presentar las situaciones histórica y contemporánea de las poblaciones que viven en las dos áreas menos estudiadas del Perú: los Andes y la selva amazónica. El estudio comienza con una revisión de la "catástrofe demográfica" que la presencia hispánica significó para las poblaciones de estas áreas. El trabajo forzado y la diseminación de nuevas enfermedades redujeron la población seis veces en el lapso de 30 años y 23 veces en un siglo. Los efectos nocivos dei "boom del caucho" y, más recientemente, del "boom del petróleo" también son revisados.

Actualmente, el área amazónica tiene la fecundidad más alta del país (6 hijos por mujer), seguida de cerca por la de la sierra andina (5.4), ambas en marcado contraste con la de Lima, la ciudad capital (2.5). El resto del artículo desagrega estas fecundidades en sus tres principales determinantes: unión conyugai, lactancia materna y uso de anticoncepción, siguiendo el modelo de Bongaarts, y estudia sus niveles relativos. Tal examen revela un nivel relativamente alto de uso anticonceptivo moderno en el Amazonas, el que es contrapuesto por una edad temprana de unión y menos lactancia materna que entre sus contrapartes en los Andes. Estas diferencias son explicadas en términos del contexto sociocultural prevaleciente en cada zona. Así, mientras las actitudes más liberales hacia el sexo y las ideas modernas entre la gente amazónica están produciendo un efecto neto incrementador de la fecundidad, en los Andes, la concepción tradicional de sus habitantes ha mantenido los factores inhibidores de la fecundidad en altos niveles, tales como una edad a la unión relativamente mayor y una extensa lactancia materna. En los Andes, sin embargo, las mujeres tienden a usar con mayor frecuencia los métodos anticonceptivos menos efectivos.

Se derivan implicancias de políticas de estos hallazgos, y se proponen recomendaciones para programas materno-infantiles y de planificación familiar más apropiados.

\section{Introducción}

El presente estudio tiene como objetivo presentar, en forma comparativa, las características reproductivas de dos tipos de población peruana que han tenido habitualmente un tratamiento poco preferencial, tanto en servicios como en investigación de salud: las poblaciones de la sierra y la selva del Perú (véase mapa 1). Es-

\footnotetext{
* Profesor, Institute of Population Studies, University of Exeter.
} 
tas áreas, a pesar del intenso mestizaje ocurrido desde la invasión española, integran a los habitantes con mayor ascendencia nativa en el Perú.

Utilizando encuestas nacionales, se presentará primero un perfil de las características de fecundidad y sus determinantes proximales en cada región. Las diferencias que resultarán de dichas comparaciones se intentarán explicar apoyándose en fundamentos socioculturales basados en estudios locales de comportamiento sexual y reproductivo. Se espera que tal simbiosis de métodos cuantitativo y cualitativo contribuya a explicar mejor los fenómenos encontrados y a proponer programas de salud reproductiva más adecuados para cada región.

Breve reseña histórica de las poblaciones de la sierra y la selva

Nos ocuparemos primero de la población de la sierra. Es ya reconocido el hecho de que, contrariamente a lo que se creía dos décadas atrás, existía una significativa población costeña en el Perú prehispánico (Varillas y Mostajo, 1990). Según diversas estimaciones, la población inca en 1520 (cuando suceden los primeros contactos con las huestes españolas) era de nueve millones. Sin embargo, esta distribución se altera radicalmente. A la masiva mortalidad indígena producida por la falta de inmunidad a desconocidos agentes bacterianos y virales, se une la destrucción desatada por guerras intestinas entre los invasores, donde los indios batallan obligadamente entre ellos, al mando de uno u otro señor feudal. Asimismo, la sola crisis producida por el resquebrajamiento del antiguo orden inca conduce a un estado de hambre e insuficiencia. Se organizan trabajos forzados - mitas- de naturaleza temporal y que requieren de grandes movimientos migratorios, fundamentalmente a zonas mineras como la de Potosí (Assadourian, 1985, citado en Varillas y Mostajo, 1990). Estos factores en su conjunto parecen haber contribuido a la catástrofe demográfica de los siglos XVI y XVII, cuando se estima que la población indígena se redujo seis veces, entre 1520 y 1550 , hasta el millón y medio de habitantes. Un siglo más tarde, esta población parece haber llegado a su mínimo: aproximadamente 400000 habitantes, produciéndose una lenta recuperación desde entonces. Desde los inicios de la crisis, la población autóctona peruana se redistribuyó, convirtiéndose en fundamentalmente serrana, hasta nuestros días, cuando un fenómeno de migración masiva hacia zonas urbanas está "repoblando" la costa, pero a expensas de un gran despoblamiento de la sierra. 
MAPA 1

Mapa político del país, 1988

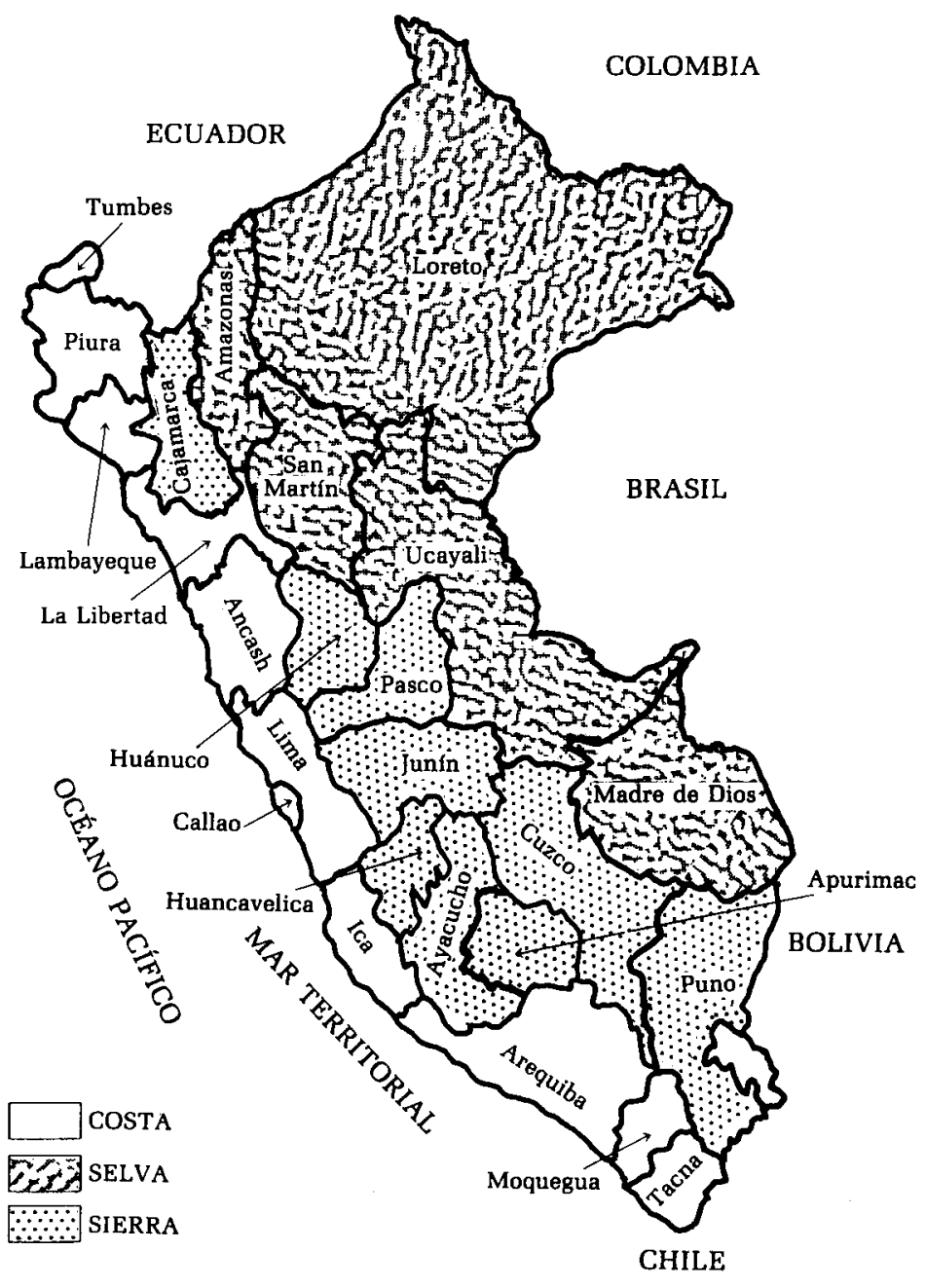


En la selva existió una situación diferente. Desde el inicio de la llegada española con el descubrimiento del río Amazonas por Francisco de Orellana (1542), se tiene información vaga sobre el tamaño de la población amazónica. Mediante técnicas indirectas, Denevan (1976, en Cook, 1981) estima que ésta era de unos 480000 habitantes antes de la invasión europea. Aunque inicialmente existió un ávido interés español por la búsqueda del idílico imperio de riqueza y paz, El Dorado, la dificultad del transporte fluvial, lo agreste de la topografía y la resistencia de los nativos hicieron que las incursiones militares en el Oriente fueran menores en escala que en la sierra. El contacto con el mundo europeo se produjo mediante la "evangelización" de nativos por parte de misioneros franciscanos, jesuítas y dominicos, quienes utilizaron variadas estrategias de conversión, incluida la fuerza (Varese, 1973) o la vida en reducciones (Regan, 1983). La costumbre en las misiones de agrupar a los nativos en pueblos fue un factor importante en la transmisión de enfermedades de procedencia europea, que diezmó a muchas poblaciones (Breyer, 1969). Como consecuencia, diversos grupos se refugiaron en "el monte" y han permanecido relativamente íntegros en su cultura hasta nuestros días. A principios del presente siglo, fenómenos como la explotación del caucho trajeron gran destrucción de las poblaciones a lo largo del río Putumayo, existiendo hasta hoy testimonios sobre personas y entidades directamente responsables de torturas y aniquilamiento (Mercier, 1979; Collier, 1981). Sin embargo, no se tiene documentación fehaciente del efecto demográfico de estos acontecimientos en la población de la zona. Por las dificultades de acceso ya citadas, hasta hace poco tiempo sólo existían gruesas estimaciones de los habitantes de la Amazonia. La baja densidad poblacional existente pareció no justificar mayores esfuerzos para su conteo. En la actualidad, se calcula que existen alrededor de 50 grupos etnolingüísticos nativos que en conjunto representan $15 \%$ de los habitantes totales de la región. El 85\% restante está compuesto por "ribereños" - mestizos descendientes de antiguos grupos nativos que, como su nombre lo indica, viven en la ribera de los principales ríos amazónicos en permanente contacto con la cultura urbana (por ejemplo, el caso de los "iquitos" del río $\mathrm{Na-}$ nay)-, y por colonos, comerciantes e inmigrantes provenientes de las otras dos regiones.

El cuadro 1 da una visión de la distribución de la población por regiones naturales a través del tiempo.

Es importante acotar que -aunque en menor proporción en la sierra y en la selva- Perú ha atravesado por diversos periodos de mestizaje y amalgamamiento étnico. Después del cruzamiento 


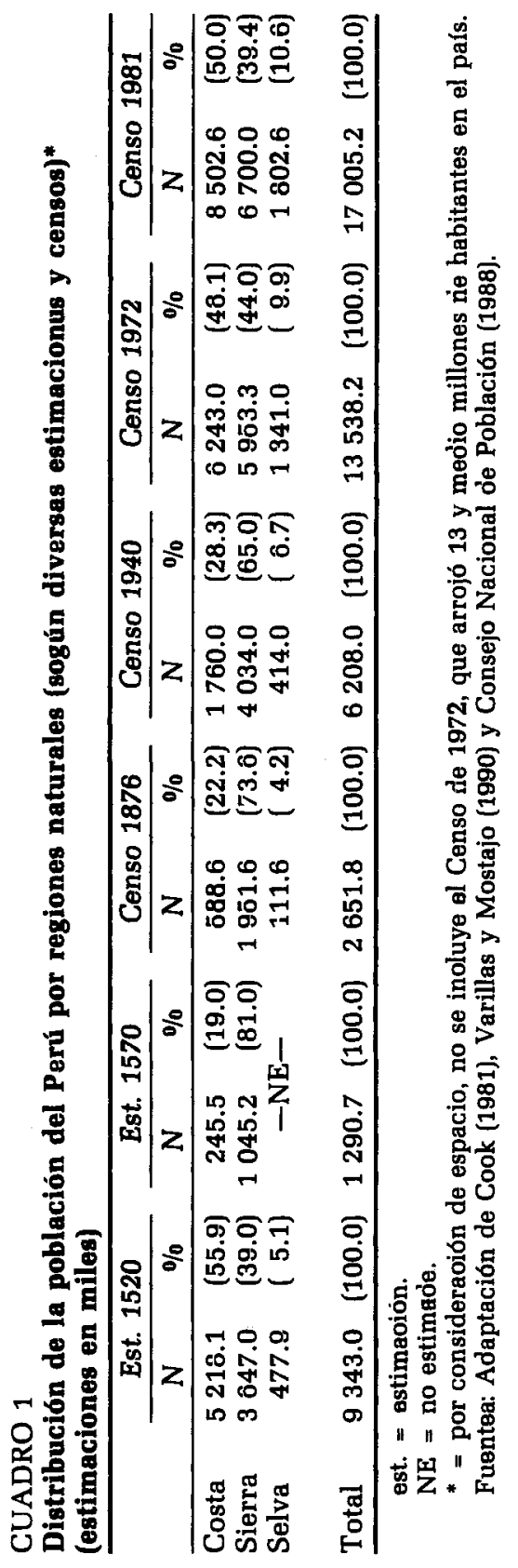


español, la composición racial se ha visto afectada por el influjo de poblaciones asiáticas y africanas, que constituían grupos esclavos o laborales; luego, especialmente durante la época del boom del guano, del salitre y del caucho, hacia finales del siglo XIX e inicios del xx, por la inmigración de europeos. De manera que, a menos que se hable específicamente de grupos nativos de ciertas zonas de selva alta, nos estamos refiriendo a grupos esencialmente mestizos. Igualmente, somos conscientes de que la delimitación geográfico-política de regiones que aquí seguimos es artificial y enturbia la existencia de claras diferencias lingüístico-culturales (por ejemplo, entre la sierra norte y la sierra sur). Sin embargo, una múltiple clasificación complicaría innecesariamente este estudio inicial. Aquí utilizaremos la hipótesis genérica de que es posible encontrar rasgos homogéneos entre poblaciones ąue comparten una región macroecológica similar, especialmente en cuanto a su comportamiento reproductivo se refiere.

\section{Fecundidad}

El estudio de las tendencias de fecundidad se encuentra dificultado por el hecho de que diferentes encuestas no han utilizado un mismo patrón de clasificación regional. Así, las dos primeras encuestas demográficas de carácter nacional, la de Aborto Inducido en Lima Metropolitana y Encuesta Comparativa de Fecundidad Rural (Peal-Pecfal) de 1969-1970, y la Encuesta Nacional de Fecundidad (Enaf) de 1977-1978, utilizaban regiones de planificación (Norte, Centro, Sur, Oriente y Lima Metropolitana) que difieren de las regiones naturales (Lima Metropolitana, resto de la costa, sierra y selva) como aparecen en posteriores informes estadísticos. Sin embargo, permiten una primera aproximación al estudio de las diferencias. El cuadro 2 muestra cómo en los ocho años que median entre ambas encuestas, existe un descenso de la fecundidad que es mayor para la región de Lima, intermedio para las otras regiones de planificación (donde se incluiría el resto de costa y la sierra, y algunas poblaciones de la selva), y menor para el Oriente, con una reducción de menos de 10 por ciento.

Más recientemente, se producen dos encuestas adicionales, la Encuesta de Prevalencia de Anticonceptivos (Enpa) de 1981, que permite confirmar la tendencia descendente de la fecundidad, y la Encuesta Demográfica y de Salud Familiar (Endes) de 1986, las que proporcionan más datos de salud materno infantil y anticoncepción. Utilizando la nueva clasificación regional se obtiene el cuadro 3, que permite desagregar la reducción de fecundidad por 
CUADRO 2

Tasas globales de fecundidad por regiones de planificación y porcentaje de reducción (según encuestas Peal-Pecfal y Enaf)

\begin{tabular}{lccc}
\hline Regiones & $\begin{array}{c}\text { Peal-Pecfal } \\
1969-1970\end{array}$ & $\begin{array}{c}\text { Enaf } \\
1977-1978\end{array}$ & $\begin{array}{c}\text { Porcentaje de } \\
\text { reducción }\end{array}$ \\
\hline Lima Metrop. & 4.30 & 3.34 & 22.3 \\
Norte & 5.92 & 5.03 & 15.0 \\
Centro & 6.51 & 5.78 & 11.2 \\
Sur & 5.89 & 5.07 & 13.9 \\
Oriente & 7.38 & 6.68 & 9.5 \\
Total & 6.93 & 5.43 & 21.6 \\
\hline
\end{tabular}

Fuente: INE (1979).

grupo etáreo en la sierra y la selva, entre la última encuesta Endes y la Enaf. Se puede apreciar que ha existido similar reducción general de la fecundidad en las dos regiones. ${ }^{1}$

Sin embargo, también se observa variación en el patrón por edad entre la sierra y la selva. Así, existe mayor disminución de la fecundidad a edades maduras en la selva, donde los niveles absolutos caen sustancialmente por debajo de los de la sierra a partir de los 35 años. La sierra, por otro lado, presenta una reducción marcada de la fecundidad en las edades intermedias, mayor en conjunto que la que experimenta la selva.

Asimismo, el cuadro permite apreciar que en sierra y selva - sobre todo en la primera- se han producido sendos incrementos en la fecundidad adolescente (15-19 años), que sobrepasan largamente las ligeras alzas vistas en Lima $(2.7 \%)$ y en el resto de la costa (7.1\%). En la selva, la tasa de fecundidad de aquel grupo alcanza niveles comparables con la del grupo de 35-39 años. Es particularmente preocupante que entre las mujeres de 20 a 29 años entrevistadas en la Endes, $47 \%$ en la selva y $41 \%$ en la sierra dieron a luz antes de los 20 años, en comparación con $24 \%$ de las de

${ }^{1}$ El valor de 5.4 en la Tasa Global de Fecundidad para la sierra dado por la Endes debe de tomarse con cautela, pues ella no incluyó los departamentos de Ayacucho, Apurímac y Huancavelica, por encontrarse en situación de violencia terrorista. Estos tres departamentos registran las más altas tasas de fecundidad del país. Realizamos un ajuste de las cifras, suponiendo una TGF promedio para las tres áreas de 6.3 (según recomienda la Endes: 29), y que los tres departamentos constituían $\mathbf{1 7 . 5 \%}$ de la población de la sierra (Censo de 1981). La nueva TGF (ponderada) para la sierra sería de 5.6, con lo que la reducción desde 1977-1978 sería de $16 \%$, en vez de $19 \%$. Sin embargo, no es posible hacer ajustes a las tasas específicas por edad, por no tener disponible sus patrones por departamentos. 


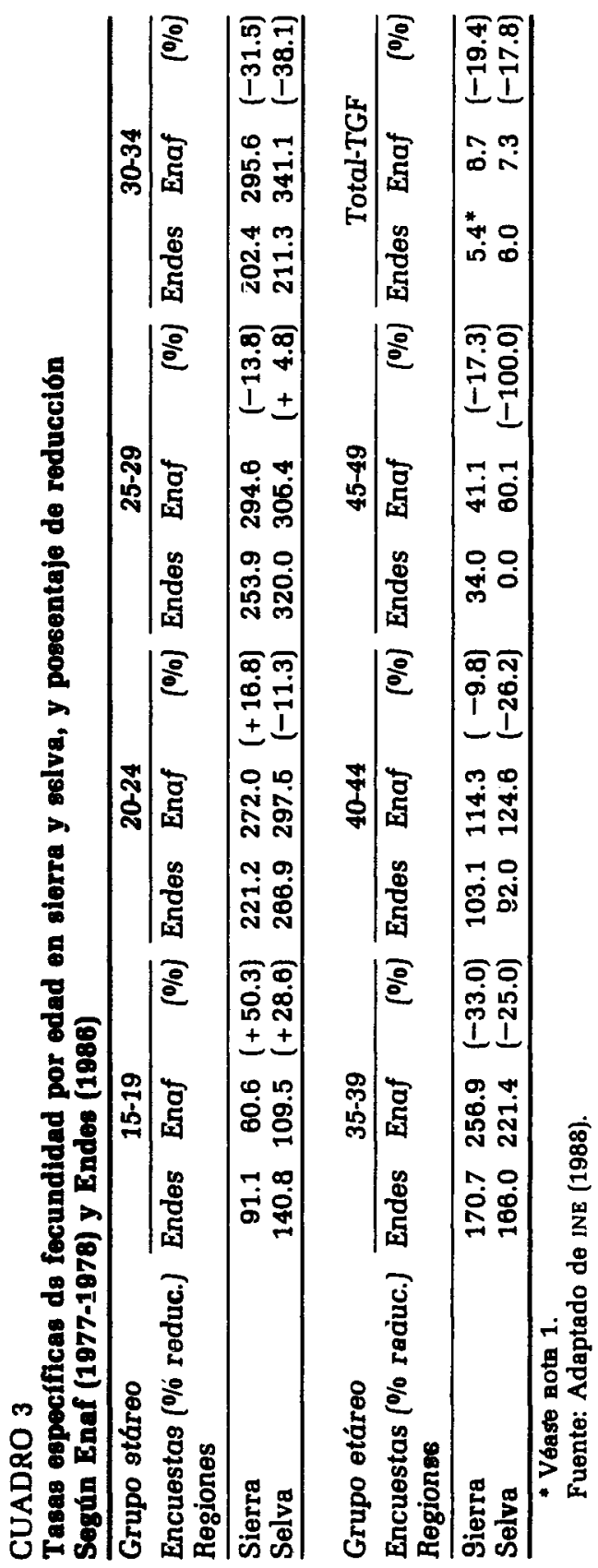


FECUNDIDAD Y COMPORTAMIENTO EN PERÚ
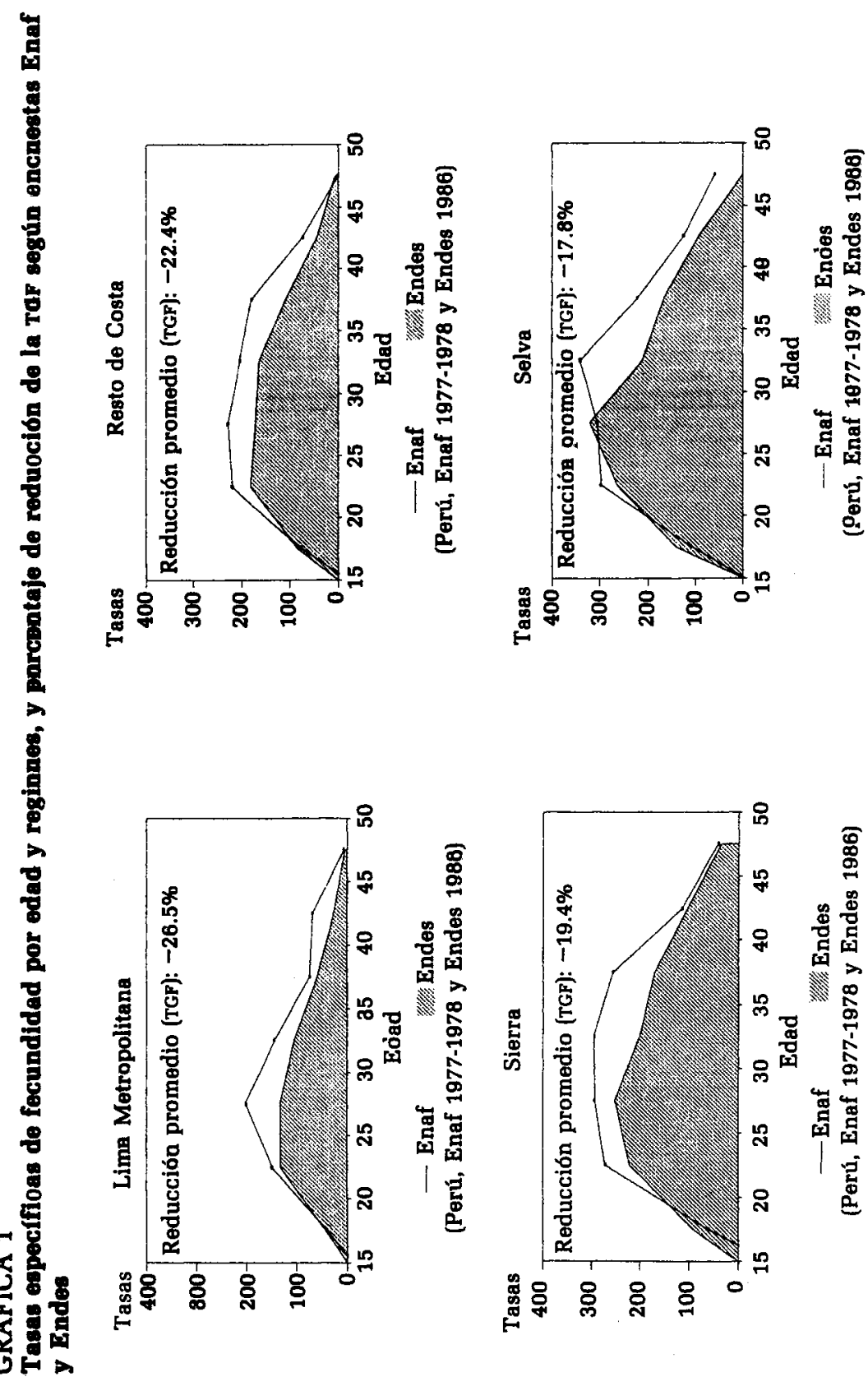


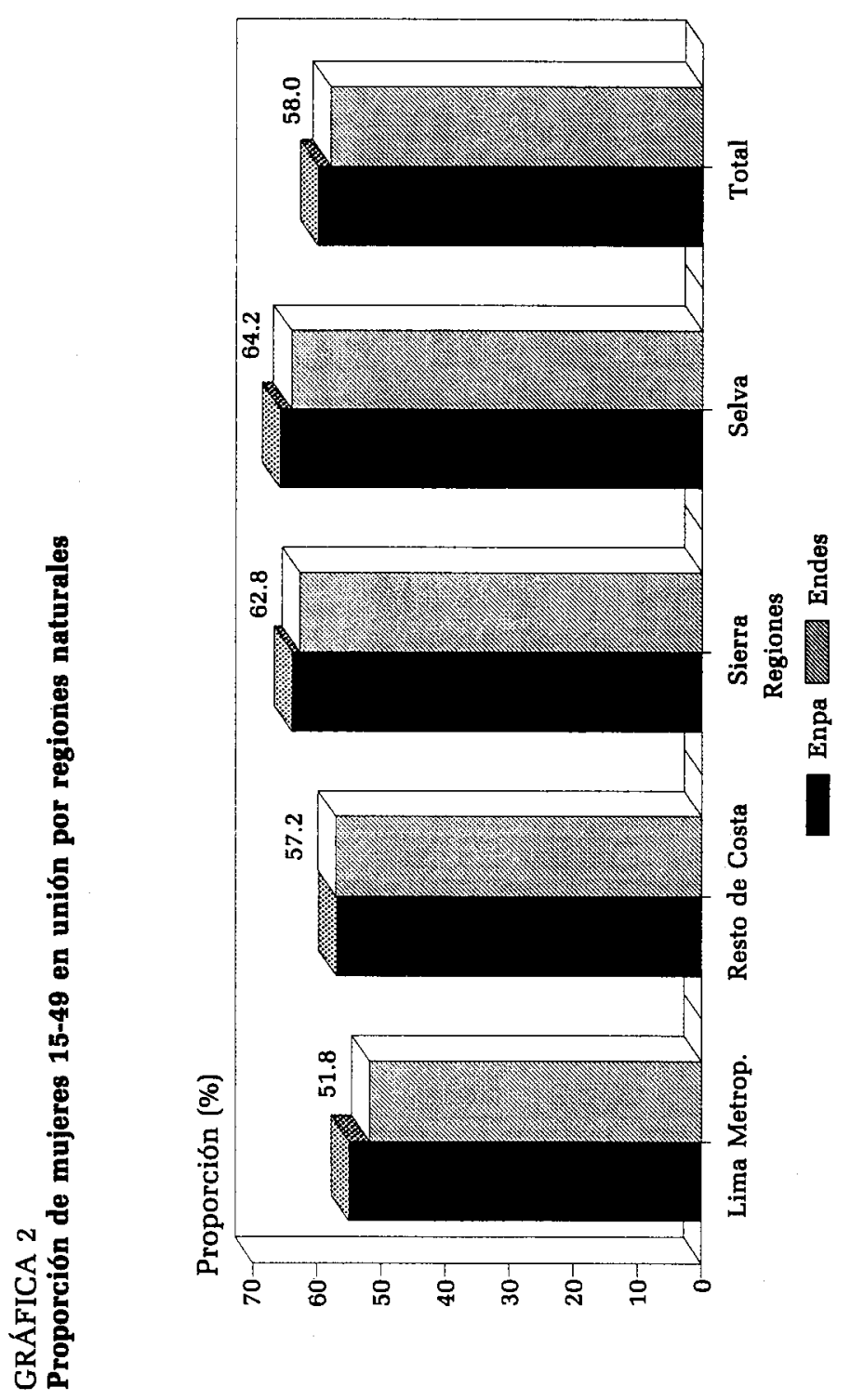

 
Lima (Ferrando et ol., 1989). La gráfica 1 permite una visión comparativa de estos cambios de la fecundidad, por edad y regiones.

\section{Nupcialidad}

El estudio de la nupcialidad es importante en Perú, ya que la fecundidad está aún altamente correlacionada con la unión conyugal. Por ejemplo, entre las adolescentes de 15 a 19 años de edad, la concepción del primer hijo vivo coincide simultáneamente con la primera unión (Singh y Wulf, 1990). Por otro lado, la tendencia de nupcialidad en Perú se ha mantenido relativamente estable en los últimos 25 años, con un porcentaje medio de unión de entre 56 y $60 \%$ de MEF. En lo que respecta a regiones, las encuestas PealPecfal y Enaf revelaron un aparente aumento en la proporción de mujeres unidas de la región de planificación Oriente (de .603 a .697), mientras las otras regiones reducían esta proporción. La gráfica 2 muestra una leve tendencia, en las poblaciones de sierra y selva, a disminuir sus proporciones de mujeres en edad fértil casadas o unidas entre las dos últimas encuestas (Enpa y Endes), aunque sus niveles son aún relativamente altos 63 y $64 \%$ respectivamente), comparados con $52 \%$ de mujeres unidas en Lima Metropolitana en 1986.

Una mejor visión la proporciona el cuadro 4, que desagrega la edad mediana a la primera unión por grupos de edades y regiones naturales. A través de éste se puede observar la tendencia creciente a retardar la primera unión entre las cohortes más jóvenes. Sin embargo, la edad media es todavía apreciablemente baja (19 años) entre las mujeres de la selva, comparada con las de las otras dos regiones (20 años), o las de Lima (22 años). Sólo las mujeres de 25 a 29 años, de la selva, se equiparan en ese rubro con sus similares de la sierra (20 años).

\section{Lactancia materna e infertilidad posparto}

Otro de los determinantes proximales de la fecundidad que nos interesa analizar es la infertilidad posparto. Ésta, a su vez, depende (en poblaciones donde la abstinencia posparto no es muy prolongada) casi exclusivamente de la práctica de la lactancia materna. Dicha lactancia va a producir una amenorrea secundaria que constituye el periodo de anovulación o infertilidad posparto (Bongaarts y Potter, 1983). Aunque nos referiremos más adelante a la amenorrea como indicador directo de la infertilidad posparto, 
CUADRO 4

Edad mediana a la primera unión entre mujeres de 25 a 49 años por grupos de edad actual y región natural, Endes 1986

\begin{tabular}{lcccccc}
\hline & \multicolumn{7}{c}{ Grupo etáreo } \\
\cline { 2 - 7 } Región & $25-29$ & $30-34$ & $35-39$ & $40-44$ & $45-49$ & Total \\
\hline Lima Metropolitana & 23.0 & 22.0 & 22.2 & 21.7 & 20.8 & 22.0 \\
Resto de la costa & 20.8 & 21.9 & 19.8 & 19.4 & 18.8 & 20.3 \\
Sierra & 20.1 & 19.3 & 20.3 & 21.0 & 19.1 & 19.9 \\
Selva & 19.9 & 19.1 & 18.0 & 17.7 & 18.3 & 18.7 \\
Total & 21.0 & 20.8 & 20.3 & 20.2 & 19.4 & 20.5 \\
\hline
\end{tabular}

Fuente: INE (1988).

aquí realizamos una discusión de los niveles y·tendencias de la lactancia materna, que es la variable susceptible de ser modificada mediante el comportamiento humano. ¿Qué diferencias fundamentales podemos encontrar en la prevalencia de lactancia materna entre las dos regiones estudiadas? El cuadro 5 resume lo encontrado en las primeras encuestas nacionales.

Existe un indicio de cierta disminución en la práctica de la lactancia materna en el país, y más marcada entre las mujeres del Oriente. Según la Enaf, la duración media de la lactancia entre las mujeres de esta zona está relacionada con la existente en Lima, y es aproximadamente cuatro meses menor que la encontrada en las otras regiones.

La encuesta Endes, utilizando un procedimiento algo diferente ${ }^{2}$ confirma la menor duración de la lactancia en la selva en re-

CUADRO 5

Duración media de la lactancia materna (en meses) en el último intervalo cerrado, por regiones de planificación y porcentaje de reducción según encuestas Peal-Pecfal y Enaf

\begin{tabular}{lccc}
\hline Regiones & $\begin{array}{c}\text { Peal-Pecfal } \\
1969-1970\end{array}$ & $\begin{array}{c}\text { Enaf } \\
1977-1978\end{array}$ & $\begin{array}{c}\text { Porcentaje de } \\
\text { reducción }\end{array}$ \\
\hline Lima Metropolitana & 9.0 & 8.7 & -3.3 \\
Norte & 14.5 & 13.8 & -4.8 \\
Centro & 14.5 & 14.3 & -1.4 \\
Sur & 15.3 & 14.5 & -5.2 \\
Oriente & 11.2 & 10.2 & -8.9 \\
Total & 13.6 & 12.6 & -7.4 \\
\hline
\end{tabular}

Fuente: Adaptado de Ortiz y Alcántara (1988).

2 En la Endes el promedio de lactancia se determinó con base en el último hijo tenido dentro de los tres años anteriores a la encuesta. Los cálculos se hicieron 
lación con la de la sierra, aproximándose aquélla más a la duración encontrada en el resto de la costa (véase gráfica 3). Una división de la muestra en mujeres menores y mayores de 30 años no parece afectar las duraciones promedio. Llama la atención observar que, contrariamente a la tendencia inicial, la duración de la lactancia materna en el país se ha incrementado en los últimos años. Aunque la duración de la lactancia parece haber sido afectada en algo por el "amontonamiento" (heaping) de valores a los 18 y a los 24 meses (el uso del método calendario en la encuesta Endes-Experimental la reduce un mes, a 15.3 meses), estimaciones basadas en tablas de vida sugieren que sí se ha producido un ligero incremento (Goldman et al., 1989). Esto también ha sido confirmado por la Encuesta Nacional de Nutrición y Salud (Ennsa) de 1984 (INE, 1986), para todas las regiones y tanto para áreas urbanas como rurales. No es posible saber si esto es debido al impacto de campañas promocionales o a la revaloración de la importancia de este alimento en la población general.

\section{Práctica anticonceptiva}

El uso de anticonceptivos en el Perú se ha incrementado rápidamente en poco tiempo. Así, la prevalencia de uso entre las mujeres unidas subió desde $20 \%$ a finales de la década de los sesenta, hasta cerca de $50 \%$ hacia mediados de los ochenta (un incremento total de $57 \%$ o de aproximadamente $3.8 \%$ anual). Las regiones que más han experimentado este ascenso han sido las interiores de costa y sierra, según se puede apreciar en el cuadro 6, al comparar los resultados de la encuesta Peal-Pecfal con los de la Enaf. Sin embargo, es importante resaltar que, según estos datos, la región Oriente exhibe tempranamente un uso de métodos superiores al de las mencionadas regiones interiores. Además, juzgando por la tasa de uso-efectividad $e,{ }^{3}$ sus mujeres utilizan en mayor proporción métodos más efectivos o "modernos"4 que sus contrapartes (incluidas las de Lima Metropolitana), quienes, en general, acu-

por el método de la incidencia-prevalencia, considerando la proporción total de mujeres que lactaba en dicho periodo (INE, 1988).

3 e es el promedio ponderado de uso-efectividad de métodos anticonceptivos usado por Bongaarts (1978) para derivar su Índice de Anticoncepción $C_{c}$. e es una fracción entre 0 y 1 y será mayor cuanto mayor sea la distribución relativa de mujeres usando métodos más efectivos (ej. esterilización o IUD).

${ }^{4}$ El dispositivo intrauterino, la pildora anticonceptiva, la esterilización quirúrgica, los esteroides inyectables, y los métodos de barrera como los preservativos y espermaticidas vaginales. 


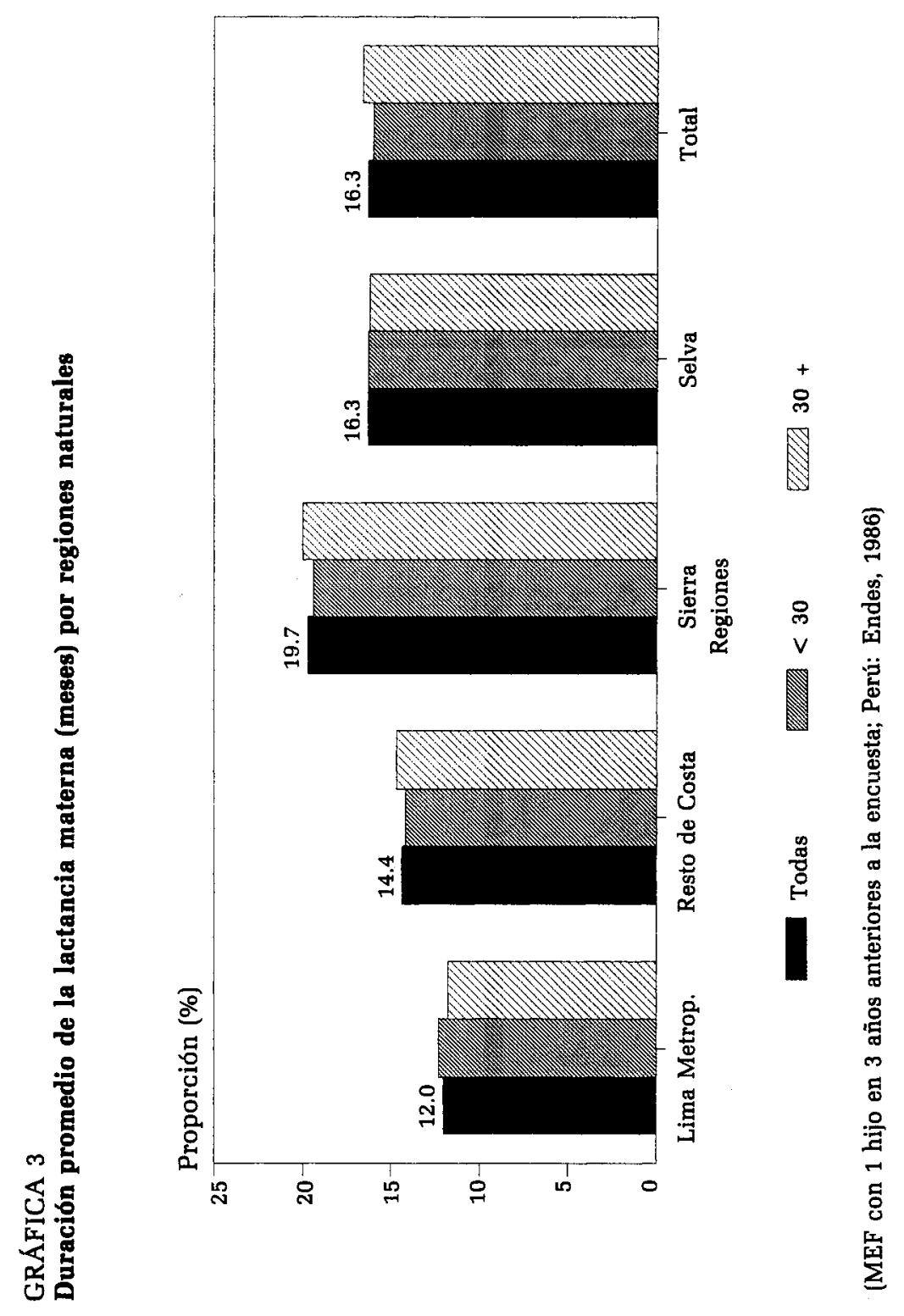


CUADRO 6

Prevalencia de uso anticonceptivo (\%) y efectividad, por regiones de planificación y porcentaje de incremento de uso, según encuestas Peal-Pecfal y Enaf

\begin{tabular}{|c|c|c|c|c|c|}
\hline \multirow[b]{2}{*}{ Regiones } & \multicolumn{2}{|c|}{ Peal-Pecfal } & \multicolumn{2}{|l|}{ Enaf } & \multirow{2}{*}{$\begin{array}{c}\text { Porcentaje de } \\
\text { incremento de uso }\end{array}$} \\
\hline & $1969-1970$ & $\mathbf{e}$ & $1977-1978$ & e & \\
\hline Lima Metropolitana & 34.9 & .78 & 48.3 & .77 & +38.4 \\
\hline Norte & 8.6 & .77 & 23.1 & .77 & +168.6 \\
\hline Centro & 9.4 & .74 & 24.9 & .75 & +164.9 \\
\hline Sur & 8.2 & .77 & 22.9 & .74 & +179.3 \\
\hline Oriente & 13.6 & .83 & 23.2 & .79 & +70.6 \\
\hline Total & 19.9 & .76 & 30.1 & .77 & +51.3 \\
\hline
\end{tabular}

Fuente: Adaptado de Ortiz y Alcántara (1988).

den a los métodos tradicionales. ${ }^{5}$ Tal aseveración será confirmada al revisar los resultados de encuestas más recientes.

En efecto, el cuadro 7 muestra los cambios producidos desde inicios hasta mediados de los años ochenta. Varios aspectos destacan. El primero, la tendencia general de la población a depender -igualmente o menos- de los métodos tradicionales para la regulación de su fecundidad. Dicho de otra manera, el incremento en la prevalencia anticonceptiva en este periodo se ha debido exclusivamente al mayor uso de métodos modernos.

En cuanto a los fenómenos regionales, se aprecia lo siguiente:

1) Las poblaciones del interior de la costa y la sierra han continuado con la tendencia iniciada una década atrás, y siguen siendo las que presentan mayor incremento en anticoncepción.

2) La sierra registra un sorprendente aumento en el uso de anticoncepción moderna (el mayor registrado por regiones), al punto que prácticamente iguala la prevalencia total de la selva; sin embargo, sus mujeres siguen dependiendo relativamente más (dos veces) de métodos tradicionales que de modernos.

3) La selva, por otro lado, aunque presenta un respetable aumento en el uso de métodos modernos, lo hace a expensas de un cierto porcentaje $(11 \%)$ de usuarias que dejan de usar los tradicionales. El patrón de cambio es similar en Lima Metropolitana. Pareciera existir aquí un cierto "traslado" a métodos más efectivos, más que un consistente aumento en su uso por parte de estas poblaciones. También puede indicar un primer estadio en la "transición anticonceptiva": un abandono por mayor descontento de mé-

\footnotetext{
${ }^{5}$ Abstinencia periódica, retiro, lavados vaginales y otros folclóricos.
} 
todos relativamente inefectivos, mientras persisten dudas y temores sobre el uso de métodos modernos. Si esta segunda explicación es correcta, dependiendo de los esfuerzos promocionales en planificación familiar, se espera un mayor uso de anticonceptivos modernos en siguientes estadios. Futuras encuestas aclararán este panorama.

Un resumen: importancia de cada determinante por regiones

Una manera de resumir el efecto de los factores antes revisados en la fecundidad regional es convertirlos en índices, de acuerdo con el modelo de determinantes proximales de.Bongaarts, y evaluar la importancia relativa de cada uno como inhibidores de la fecundidad. En un intento por comparar cifras seguiremos, en lineas generales, la misma metodología adoptada en un estudio de Ortiz y Alcántara (1988), quienes utilizan el modelo para derivar niveles y tendencias entre las encuestas Peal-Pecfal de 1969-1970 y Enaf de 1977-1978. ${ }^{6}$ Cabe resaltar, sin embargo, algunas diferencias entre tal estudio y el presente:

1) Como se ha visto, las encuestas Peal-Pecfal y Enaf subdividen sus resultados por regiones de planificación, mientras que las posteriores encuestas informan por regiones naturales. Las únicas regiones similares para comparaciones generales son Lima Metropolitana y la región Oriente, que es una submuestra de la actual selva. También se podrán comparar resultados nacionales.

2) Las encuestas Peal-Pecfal y Enaf utilizan datos de lactancia basados en el último intervalo cerrado, es decir, del penúltimo hijo en mujeres unidas que tuvieron dos hijos vivos en el transcurso de los seis años anteriores a la encuesta (método del "estado actual"). En este estudio, los datos están basados en las mujeres que tuvieron un hijo en los tres años anteriores a la encuesta y las duraciones son calculadas por el método de la "incidencia-prevalencia" (iNE, 1988); ambos métodos están sujetos al mismo problema de heaping y dan resultados que no difieren fundamentalmente el uno del otro.

\footnotetext{
${ }^{6}$ Por ejemplo, nuestras Tasas de Fecundidad Marital están basadas en añosmujer en unión, tal como las deriva la encuesta Endes. Asimismo, hemos excluido en el cálculo de usuarias de anticonceptivos a todas aquellas mujeres en unión que estaban lactando bebés de seis meses o menos, por considerarlas que se encuentran incluidas entre las que presentan amenorrea posparto. La ENDES encuentra cerca de $15 \%$ de MEF en unión que usan algún método anticonceptivo y están lactando menos de siete meses.
} 


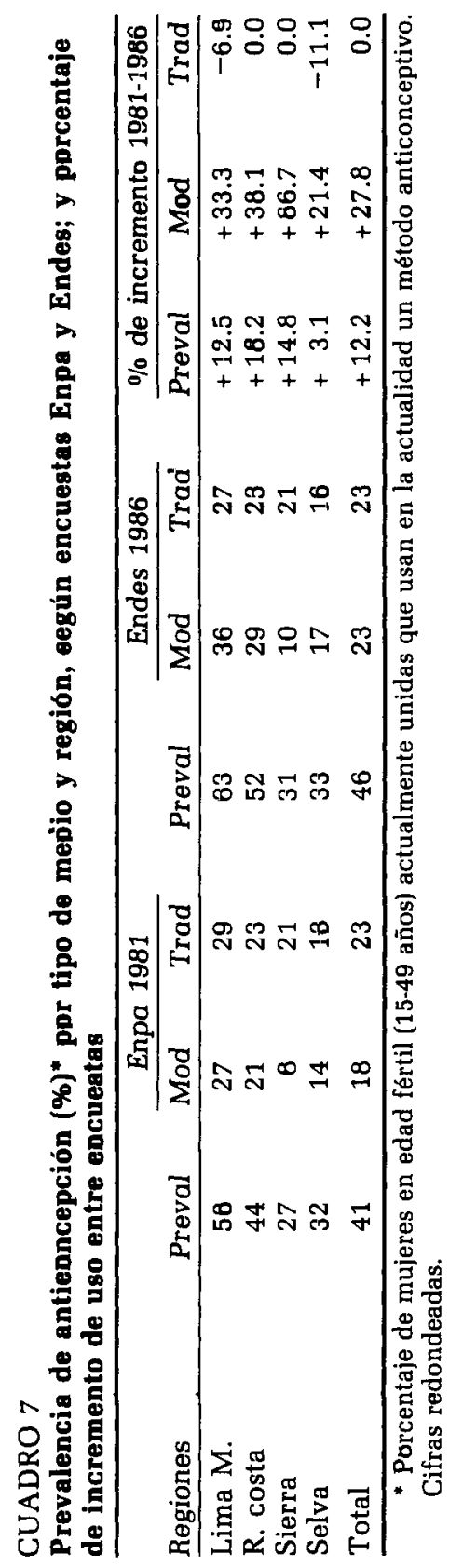


3) Para el cálculo del índice de infertilidad posparto $\left(C_{i}\right)$ en este trabajo, la duración de la infertilidad (i) se ha tomado directamente de las respuestas sobre la amenorrea posparto, como lo recomienda el autor. El estudio de Ortiz y Alcántara recurrió a una estimación de i basada en la duración de la lactancia materna, que da cifras algo más altas, sobreestimando el efecto de la lactancia en la inhibición de la fecundidad (con el dato de la lactancia, i resulta 10.37 a nivel nacional, mientras que directamente es 9.1 , una diferencia de 14 por ciento).

El modelo será presentado sólo para la encuesta Endes de 1986. La anterior encuesta, Enpa, no permite completar los cálculos por no presentar información sobre lactancia materna.

Los datos revisados en las secciones anteriores son aplicados -a nivel nacional y por regiones- a las siguientes fórmulas:

$$
\begin{aligned}
& \mathrm{TGF}=C_{m} \times C_{c} \times C_{a} \times C_{i} \times \mathrm{TF}, \\
& \mathrm{TM}=\mathrm{TGF} / C_{m}, \\
& \left.\mathrm{TN}=\mathrm{TM} / C_{c} \times C_{a} \text { (o } 15.3 \times C_{i}\right), \mathrm{y} \\
& \mathrm{TF}=\mathrm{TN} / C_{i}
\end{aligned}
$$

donde

TGF: Tasa Global de Fecundidad

TM: Tasa de Fecundidad Marital

TN: Tasa de Fecundidad Natural

TF: Tasa Total de Fertilidad

$C_{m}$ : Índice de matrimonio (unión)

$C_{c}$ : Índice de anticoncepción

$C_{a}$ : Índice de aborto inducido, $\mathrm{y}$

$C_{i}$ : Índice de infertilidad posparto ${ }^{7}$

Los resultados se presentan en el cuadro 8. Se pueden apreciar varias situaciones.

\section{Resultados a nivel nacional}

A nivel nacional, hay una reducción total de la tasa global de fecundidad en los nueve años que median entre las encuestas de

\footnotetext{
${ }^{7}$ Por limitaciones de espacio, aquí no se detallarán los fundamentos ni procedimientos del modelo. El lector interesado puede referirse a Bongaarts (1978 y 1982) y Bongaarts y Potter (1983). Para los cálculos detallados del presente estudio, contactar al autor.
} 
$1977-1978$ y 1986 , de $21 \%$. Esta reducción se descompone evaluando el cambio en cada uno de los índices de los determinantes proximales, más el cambio en la Tasa Total de Fertilidad, y un factor de interacción entre los componentes. ${ }^{8}$ Es así que la reducción se debe fundamentalmente al incremento en el uso y efectividad de métodos anticonceptivos (reducción conjunta de 18\%). El leve aumento en la lactancia materna registrada contribuye a reducir la fecundidad en $5 \%$ extra. Debido a los pocos cambios habidos en la proporción de mujeres en unión, este factor contribuye escasamente con un 3\%. Según el modelo, sin embargo, la Tasa Total de Fertilidad (TF) aumenta de 15.44 a 15.68 (1.6\%), quedando la interacción responsable de un aumento de 3.7 por ciento.

\section{Resultados a nivel regional}

Lo que interesa examinar ahora es la contribución de los diferentes determinantes a la Tasa Total de Fertilidad (TF) observada recientemente en cada región, en especial en la sierra y la selva (datos de la Endes 1986). Para esto, el procedimiento es más simple que en el caso anterior. Esta vez, se resta la fracción inhibidora de cada índice $C_{m}, C_{c}$ y $C_{i}$, de 1 (que es la no inhibición); el resultado es la fracción por la que el índice efectivamente reduce la $T F$ y se puede expresar en porcentaje. De esta manera, tenemos las contribuciones:

Nacional Lima M. R. Costa Sierra Selva

De la proporción de

mujeres casadas:

\begin{tabular}{|c|c|c|c|c|c|}
\hline $\begin{array}{l}\left(1-C_{m}^{*}{ }^{*} 100\right) \\
\text { De la práctica }\end{array}$ & $43.1 \%$ & $54.5 \%$ & $44.1 \%$ & $38.0 \%$ & $30.9 \%$ \\
\hline $\begin{array}{l}\left(1-C_{c} * 100\right) \\
\text { De la lactancia ma- }\end{array}$ & $36.5 \%$ & $59.6 \%$ & $46.7 \%$ & $21.8 \%$ & $28.2 \%$ \\
\hline tern & $27.3 \%$ & $17.0 \%$ & $21.3 \%$ & $34.0 \%$ & $31.0 \%$ \\
\hline
\end{tabular}

${ }^{8}$ Esta evaluación se realiza aplicando la siguiente relación entre los años 2 (Endes) y 1 (Enaf):

$$
\frac{\mathrm{TGF} 2}{\mathrm{TGF} 1}=\frac{C_{m} 2 \times C_{c} 2 \times C_{a} 2 \times C_{i} 2 \times \mathrm{TF} 2}{C_{m} 1 \times C_{c} 1 \times C_{a} 1 \times C_{c} 1 \times \mathrm{TF} 1}
$$

y los cambios proporcionales (por ejemplo, $P_{j}=$ TGF2/TGF1 - 1) se expresan en la formula equivalente: $P_{f}=P_{m}+P_{c}+P_{a}+P_{i}+P_{r}+I\left(P_{r}\right.$ es el cambio debido al resto de determinantes proximales e $I$ es la interacción). 


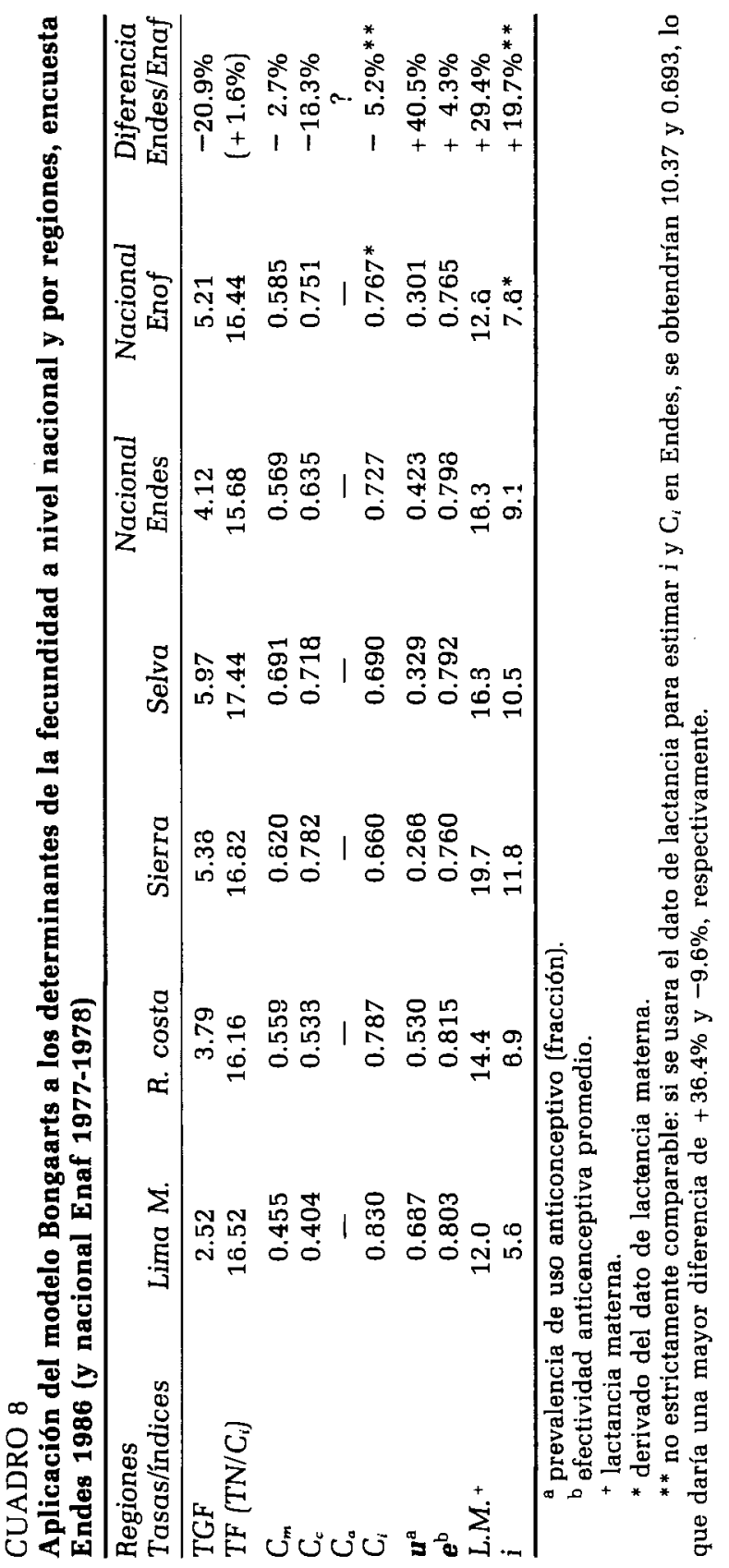


Aquí se puede evaluar la contribución relativa de cada índice, nacional y regionalmente. Así, es interesante observar que, a nivel nacional, la proporción de mujeres casadas es la que contribuye más a la reducción de la TF, mientras que en Lima y el resto de la costa la práctica anticonceptiva es el factor predominante. Por otro lado, la influencia de la lactancia materna es algo menor en el país y apreciablemente menor en Lima.

Respecto a la comparación entre sierra y selva, las diferencias son notables. En general, la práctica anticonceptiva es el factor de menor peso, aunque relativamente hablando, la selva contribuye al descenso de la capacidad fértil en mayor porcentaje que la sierra (y nuevamente se aprecia que la efectividad del uso de métodos e-debido a la mayor proporción de métodos modernoses mayor en la selva). En la sierra, los efectos de nupcialidad y de lactancia materna son los que más contribuyen a este descenso. Si utilizamos una Tasa Total de Fertilidad promedio de 15.3 para todas las regiones, de acuerdo con lo propuesto por Bongaarts (1978), podemos apreciar mejor las contribuciones relativas en la gráfica 4.

Este modelo también permite dar una idea del estadio de transición de la fecundidad en el que el país se encontraría (Bongaarts, 1982). De acuerdo con los indicadores, Perú estaría entrando en el estadio III (ejemplo: Jamaica o Colombia en el año 1976). Sin embargo, como regiones, la sierra y la selva se encontrarían aún en el estadio II (ejemplo: Líbano o Malasia en el año 1976).

Es de resaltar el hecho de que, hacia el estadio III, el modelo considera que el aborto inducido ya contribuye al descenso de la fertilidad total (factor que no hemos tomado en cuenta aquí) en $4 \%$; esto equivale a una tasa de aborto aproximada de 0.1 o un aborto por cada diez mujeres al final del periodo reproductivo. Finalmente, el factor que menos se ajusta a las predicciones de estadios demográficos es la contribución de la lactancia materna. Según el modelo, Perú debiera tener una duración promedio de amenorrea posparto de aproximadamente 8; sin embargo, ésta es mayor (9.1), un hallazgo obviamente positivo.

\section{Culturas y comportamiento sexual-reproductivo}

En un intento por comprender mejor las diferencias encontradas en los determinantes próximos de la fecundidad entre la sierra y 


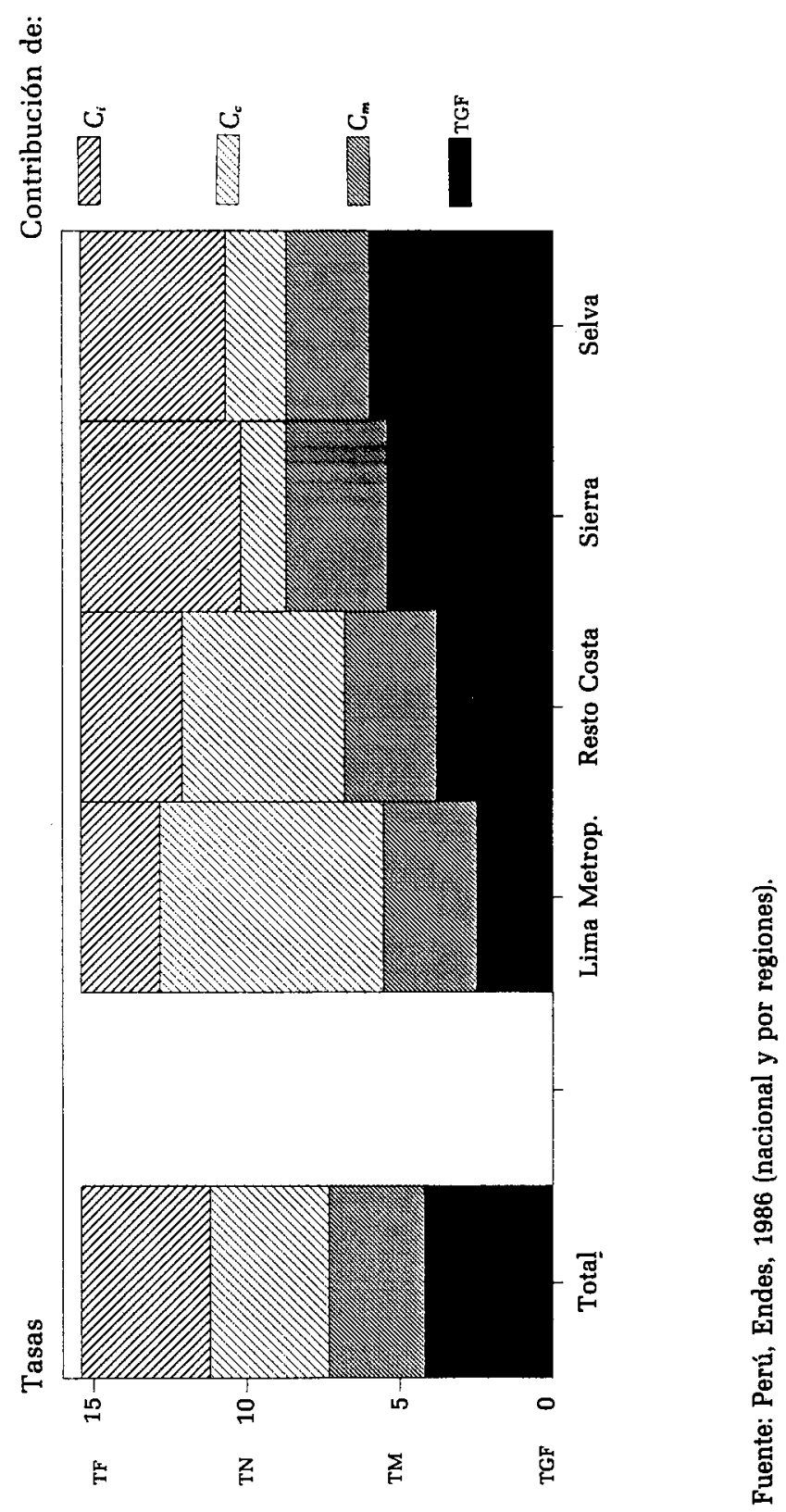


la selva, revisaremos las características culturales que sus poblaciones presentan, particularmente en materia de comportamiento sexual y reproductivo. De esta revisión surgirá una hipótesis de trabajo para una futura validación, que se espera ayude a predecir la tendencia en el comportamiento reproductivo en ambas regiones.

Para iniciar este somero análisis cualitativo, nos referiremos a un estudio original de Beaver (1975), quien investigó la transición demográfica en América Latina. Usando datos agregados, demostró una relación entre el periodo de mayor declinación de la natalidad y la "composición racial" de un país como una medida de lo que él llamó "de apertura y (o) exposición a influencias modernizantes". Dividió a los países en las ocho categorías siguientes:

\begin{tabular}{|c|c|c|c|}
\hline $\begin{array}{l}\text { EU } \\
\text { Argentina } \\
\text { Uruguay }\end{array}$ & $\begin{array}{l}E U+\mathrm{pAF} \\
\text { Cuba } \\
\text { Pto. Rico }\end{array}$ & $\begin{array}{l}\mathrm{EU}+\mathrm{pAM} \\
\text { Chile } \\
\text { Costa Rica }\end{array}$ & $\begin{array}{l}\text { AF o IN } \\
\text { Guyana } \\
\text { Jamaica } \\
\text { Haití } \\
\text { T. Tobago }\end{array}$ \\
\hline $\begin{array}{l}M X+s A F \\
\text { Brasil } \\
\text { Panamá } \\
\text { Rep. Dominic. }\end{array}$ & $\begin{array}{l}A M+e E U+A F \\
\text { Colombia } \\
\text { Nicaragua }\end{array}$ & $\begin{array}{l}\text { MZ (AM + eEU) } \\
\text { El Salvador } \\
\text { Honduras } \\
\text { México } \\
\text { Perú } \\
\text { Venezuela }\end{array}$ & $\begin{array}{l}\text { AM } \\
\text { Bolivia } \\
\text { Ecuador } \\
\text { Guatemala } \\
\text { Paraguay }\end{array}$ \\
\hline
\end{tabular}

$(E U=$ Europea, $A F=$ Africana, $A M=$ Amerindia,$I N=I$ ndia del Este, $M X=$ Mixta, $M Z=$ Mestiza, $p=$ parte, $s=$ sustancia, $e=$ escasa)

Encontró que países fundamentalmente compuestos de población mestiza, como El Salvador, Honduras y México experimentaron declinaciones de la fecundidad que eran recientes y modestas, comparadas con países como Argentina, Uruguay, Cuba y Puerto Rico, donde el descenso de la fecundidad se había iniciado tempranamente y había sido sustancial. Beaver luego procedió a realizar análisis de regresiones con otra serie de variables socioeconómicas. Aunque el modelo se puede criticar como muy genérico y basado en datos agregados, es un primer intento de identificar características que hoy llamaríamos étnico-culturales en el comportamiento reproductivo de poblaciones.

En Perú no se han realizado estudios detallados que determinen la composición étnico-cultural de sus poblaciones. Como se 
mencionó en la introducción, el creciente mestizaje ha determinado que las categorías no sean tan claras. Así, aunque es posible identificar aún grupos de amerindios, blancos (o criollos), asiáticos, africanos y nativos, el resto de la población es fundamentalmente mestiza.

Sin embargo, es posible realizar una descripción general de las características culturales de las poblaciones por áreas globales de residencia. Empezaremos por la sierra.

\section{La sierra}

La sierra está compuesta fundamentalmente de amerindios, descendientes de los incas que antes la poblaban. Muchas de sus costumbres actuales tienen antecedentes en épocas remotas, como la fiesta del cortcmelo. Esta fiesta popular es derivada de una ceremonia que los incas realizaban para celebrar el destete de los hijos primogénitos, hacia los dos años de edad. Según el cronista Inca Garcilaso de la Vega en sus Comentarios reales, publicados por vez primera en 1609, "les trasquilaban el primer cabello con que habían nacido... y les ponían el nombre propio que habían de usar (libro IV: p. 22). Garcilaso describe cómo los parientes e invitados cortaban el pelo del infante y depositaban ofrendas para la familia, de manera similar a como hoy se realiza. Sin embargo, hoy se lleva a cabo al año de edad y no tiene el sentido mágicoreligioso de entonces (Nyrop, 1981).

Existen asimismo entre los incas otras costumbres relacionadas con la fecundidad que parecen ser base del comportamiento actual de la población serrana. Así, Garcilaso narra que se le otorgaba un alto valor a la virginidad, originado en la condición de las mujeres escogidas para el Inca, quien era considerado una deidad. Las viudas guardaban clausura por un año y las que tenían hijos no se volvían a unir "sino que vivían en continencia" (pp. 7-17). Los casamientos eran decretados por el Inca, anual o bianualmente y existía una política de edad mínima de unión: los varones se casaban de 24 años o más, mientras que "las mozas" debían de tener de 18 a 20 años; "casarlos de menor edad se consideraba una muchachería" (p. 18). Asimismo, debían tener consentimiento de sus padres para legitimar la unión y los hijos. Al parecer, las madres parían sin ayuda de una partera. Se practicaba la abstinencia posparto durante la lactancia porque de lo contrario "decían que era malo y enflaquecía a la criatura" (p. 24). El cronista admite la existencia de prostitutas "que los incas permitían para evitar mayores daños"; éstas eran llamadas pampayrunas, o muje- 
res del campo, públicas. Más adelante se puede apreciar nuevamente el tradicionalismo de esta civilización. Al comentar sobre las leyes que diera el inca Pachacútec, Garcilaso relata cómo el adulterio era castigado con la muerte. Igualmente hace referencia a una ley sobre la vestimenta; dice que Pachacútec decretó:

... que los indios se adornasen moderadamente; la cual ley guardan hasta ahora los indios tributarios que se contenían con el vestido común y ordinario y así excusan mucha corruptela que los indios galanos y soberbios suelen sausar (libro vi: 184).

Este sistema monárquico y patriarcal es destruido con la imposición de la cultura española, que penetró primordialmente a través de la religión. Así, la cultura andina de hoy está fuertemente matizada de ritos "paganos" que son una mezcla de catolicismo y cultura indigena original. Ejemplos de esto son el bautismo, como una forma de evitar que la criatura contraiga una enfermedad, y el sistema de compadrazgo que conlleva; también las múltiples fiestas de santos y devotos, procesiones, que refuerzan creencias y supersticiones pararreligiosas.

En cuanto a rasgos individuales, pareciera que el origen incaico más la mezcla española han derivado en un personaje reservado y de actitudes tradicionales. No sin un cierto prejuicio occidentalista, ha sido descrito como poseedor de una "personalidad sumisa":

Son extremadamente introvertidos y se distancian de los demás; muestran excesivo respeto por los otros, desvalorando su propio potencial; pueden incluso humillarse con tal de obtener algo de otra persona (Matos et al., 1969).

El tradicionalismo de la población andina y la sumisión de la mujer a la dominación masculina desde el tiempo del incanato ha sido extensamente documentado (Burkett, 1978; Cornejo, 1983; $\mathrm{Babb}, 1985)$, aunque sin ofrecer relaciones con el comportamiento reproductivo. Este tradicionalismo parece persistir en la actualidad, cuando se encuentra mayor proporción de adolescentes en Cuzco (sierra) que en Iquitos (selva) que afirman ser católicos ( $89 \%$ vs. $79 \%$ ) o que se consideran muy religiosos ( $51 \%$ vs. $39 \%$ ) (Fort, 1991). También se refleja en el menor número de mujeres de la sierra (88\%) que creen que es aceptable transmitir mensajes de planificación familiar por radio o televisión, en comparación con las de la selva (94\%), según la Endes (INE, 1988).

Sin embargo, hemos visto cómo este tradicionalismo tiene as- 
pectos positivos para la limitación de la fecundidad, como son el mantener una edad de unión relativamente más alta que la de la selva y hacer posible una mayor duración de la lactancia materna. Asimismo, se ha observado cómo su población, aunque depende aún grandemente de métodos tradicionales para la limitación de la fecundidad, está incrementando el uso de métodos modernos de anticoncepción. Estos aspectos serán discutidos en conjunto en las conclusiones.

\section{La selva}

De la misma manera que en la sierra, la población de la selva es producto del mestizaje de los nativos originales, en este caso con algunos indios de la sierra y con oleadas de blancos venidos en los diferentes periodos de auge de la explotación del caucho y la madera (y más recientemente, del petróleo). Los nativos, a pesar de la feracidad que se les atribuye en la defensa de sus territorios (por ejemplo, la de los campas o asháninka, en Varese, 1973, o la de los quichwa del Napo, en Mercier, 1979) son conocidos como gente amistosa y sociable entre ellos y con otros. Entre sus características se incluyen un amor a la libertad personal y un sistema social basado en la generosidad y la reciprocidad (PUCP, 1971). Los ribereños, nativos transculturalizados o descendientes de éstos, que habitan comunidades o caseríos a lo largo de los principales ríos de la Amazonia, tienen una amplia apertura hacia la cultura occidental y poseen una menos marcada división social y de mano de obra que sus contrapartes andinos. Además de ser observación personal del autor, al haber trabajado en ambas culturas, existen algunas descripciones publicadas sobre la amplia libertad sexual de que gozan estos habitantes de la Amazonia. Regan (1983), en un estudio extensivo sobre los sistemas sociales y religiosos en el área, describe cómo su gente piensa que "las relaciones sexuales son algo natural, y son frecuentes las relaciones premaritales" (Regan, 1983: 222); también anota que, a pesar de que tienen "mucho respeto a la vida y desea [la gente] tener hijos... . utilizan anticonceptivos y abortivos cuando sienten que no pueden criar varios niños a la vez" (Regan, 1983: 223). Muchas de sus creencias y supersticiones, a diferencia de los de la gente de la sierra, se relacionan con la vida sexual. Por ejemplo, hay numerosas leyendas sobre el delfín rosado, animal al que se cree dotado de poderes sexuales extraordinarios: sale del agua en las noches, disfrazado de humano, para seducir a jóvenes mujeres; pescadores que han recuperado su vigor sexual después de haber tenido relaciones con 
uno de estos animales, etc. Partes del delfín son utilizadas para preparar pociones mágicas que se dice atraen al sexo opuesto ${ }^{9}$ (Regan, 1983; Rumrrill, 1985).

Esta supuesta liberalidad sexual podría explicar el fenómeno de una edad de unión extremadamente temprana en la región, o el hecho de que los porcentajes más altos de disolución de la primera unión en el Perú corresponden a las mujeres de la región del Oriente (INE, 1979). Si asumimos que sus habitantes son más propensos a adoptar innovaciones de la cultura occidental, esto parecería indicar un mayor conocimiento y uso de la anticoncepción moderna entre ellos, así como el mayor porcentaje de mujeres con una actitud positiva hacia los mensajes de planificación familiar. Sin embargo, también podría ser el motivo por el cual la población femenina dedica menor tiempo a la lactancia materna, fenómeno modernizante no deseable. Estos aspectos se discutirán en conjunto en las conclusiones.

\section{Conclusiones e implicancias}

Hemos visto que existen similitudes y diferencias entre las poblaciones de la sierra y de la selva, ya sea al comparar sus indicadores entre sí o con los existentes en el resto del país. Entre las similitudes podemos encontrar que en todos los indicadores revisados, la sierra y la selva de Perú están consistentemente en desventaja, en comparación con la situación del resto del país. Así, dichas poblaciones tienen mayor fecundidad, menor reducción de la fecundidad, mayor proporción de mujeres en unión, menor edad mediana a la primera unión, mayor duración promedio de la lactancia materna y menor uso de anticoncepción efectiva que las poblaciones de Lima Metropolitana y del resto de la costa.

Sin embargo, entre las dos regiones menos favorecidas también se encuentran diferencias. Al revisar éstas y relacionarlas con el contexto social de sus poblaciones, podemos esbozar las siguientes hipótesis de caracterización:

1. Que la población de la selva presenta una mayor permisividad sexual y apertura a la cultura occidental que la de la sierra; esta característica es positiva en cuanto parece permitir un

${ }^{9}$ Algunos de estos relatos y leyendas, y su relación con la cultura amazónica han sido recogidos en un documental titulado "Iquitos" (la ciudad principal en el Amazonas peruano), producido y dirigido por Paul Yale y Andy Harries para el canal 4 de televisión de Londres, marzo de 1990. 
mayor acercamiento y uso de la anticoncepción moderna; sin embargo, también está produciendo efectos deletéreos, como una mayor proporción de mujeres que ingresan a la vida reproductiva, y además, tempranamente; tasas de fecundidad global y adolescente altas, y la tendencia a una menor duración promedio de la lactancia materna.

2. Que la población de la sierra ha exhibido un mayor grado de tradicionalismo, evidenciado por una mayor restricción del comportamiento sexual. Esto ha tenido efectos positivos en el control de la fecundidad, que aún se mantienen, como una edad de unión mayor que la de la selva, y la persistencia de una larga duración promedio de la lactancia materna. Entre los efectos negativos del comportamiento conservador se encuentra la dependencia aún marcada hacia el uso de los métodos anticonceptivos tradicionales. Por otro lado, algunas normas sociales en la sierra se erosionan con rapidez, algunas en favor de la limitación de la fecundidad, como el uso anticonceptivo moderno, que está incrementándose más aceleradamente que en la selva; sin embargo, esta erosión de valores también ha producido un dramático aumento en las uniones tempranas, lo que añade un periodo mayor de exposición al riesgo de embarazo en cohortes jóvenes.

Lo revisado anteriormente permite predecir que, de no mediar acciones efectivas pero apropiadas a cada situación regional, podremos ver que la población de la sierra disminuirá su fecundidad e incrementará el uso de anticoncepción en mayor proporción que la de la selva.

\section{Recomendaciones}

Hacia este punto del estudio, podemos recomendar algunas acciones efectivas, basadas en los niveles y diferencias encontradas:

1. Tanto en la sierra como en la selva de Perú, es imperativo realizar campañas educativas - fundamentalmente en las escuelas- sobre las desventajas de la unión temprana y las ventajas del espaciamiento y limitación de la fecundidad.

2. En la sierra se debe hacer hincapié en las limitaciones de los métodos tradicionales de anticoncepción, aunque enseñando a usarlos más eficazmente, utilizando términos y referencias locales (Fort, 1989); respetar y apoyar valores positivos como la lactancia materna y la integración de la familia. 
3. En la selva se debe desalentar la unión temprana (mediante programas de educación continuada, por ejemplo) y estimular la práctica de la lactancia materna. Igualmente, debe difundirse el uso de la anticoncepción moderna, la que se prevé encontrará menor resistencia que en la sierra.

4. Finalmente, los programas de planificación familiar deberán tener en cuenta las características étnico-culturales de cada medio, adaptando lenguajes y contenidos en la difusión y entrega de servicios.

Es menester indicar, sin embargo, que estas medidas detalladas no suplirán la necesidad impostergable de desarrollar las zonas interiores del país, olvidadas por lustros, y procurar educación y empleo a nuestras mujeres, para que adquieran el status necesario para ejercer sus derechos humanos. ${ }^{10}$

\section{Bibliografía}

Babb, F. (1985), "Women and Men in Vicos, Peru: a case of unequal development", en W. Steind (eds.), Peruvian Contexts of Change, Boston, Hall.

Beaver, S.E. (1975), Demographic Transition Theory Reintepreted: an Application to Recent Natality Trends in Latin America, London, Lexington Books.

Breyer, Wenceslao (1969), "Carta a su Hermano, Sacerdote Jesuita en Praga, escrita en la reducción de Santiago de Laguna, el 18 de junio de 1699", en Mauro Matthei (comp.), Cartas e Informes de Misioneros Extranjeros en Hispanoamérica, primera parte, Santiago, Universidad Católica de Chile, pp. 188-194.

Bongaarts, J. (1978), "A Framework for Analyzing the Proximate Determinants of Fertility", en Population and Development Review, vol. 4, núm. 1: 105-132.

(1982), "The Fertility-Inhibiting Effects of the Intermediate Fertility Variables", en Studies in Family Planning, vol. 13, núm. 6/7: 179-189.

${ }^{10}$ Desde que el artículo original fue escrito, han aparecido resultados de la segunda fase de las encuestas de Demografía y Salud Familiar (Endes II) confirmando esta predicción. Así, por primera vez la sierra ha alcanzado una prevalencia de uso anticonceptivo mayor que la de la selva (49.5 contra $48.3 \%$ ), habiendo incrementado su uso anticonceptivo moderno $112 \%$ entre 1986 y 1991-1992, en contraste con la de la selva $(54.4 \%$ de incremento) (INEI, 1992$)$. El reto para los planificadores es obvio. 
Bongaarts, J. y R.G. Potter (1983), Fertility, Biology, and Behavior: an Analysis of the Proximate Determinants, Londres, Academic Press.

Burkett, E. (1978), "Indian Women and White Society: the case of sixteen century Peru", en A. Lavrin (eds.), Latin American Women-Historical Perspectives, Greenwood Press.

Collier, R. (1981), Jaque al Barón, la historia del caucho en la Amazonia, Lima, Biblioprenta.

Consejo Nacional de Población (1989), Perú: hechos y cifras demográficas, Lima.

Cook, D.N. (1981), Demographic Collapse. Indian Peru, 1520-1560, Cambridge, Cambridge University Press.

Cornejo, R. (1983), 'La situación de la mujer", en El Sur Peruano: realidad poblacional, Lima, AMIDEP.

Ferrando, D., S. Singh y D. Wulf (1989), Adolescentes de hoy, padres del mañana: Perú, Nueva York, Alan Guttmacher Institute.

Fort, A. (1989), "Investigating the Social Context of Fertility and Family Planning: A Qualitative Study in Peru", en International Family Planning Perspectives, vol. 15, núm. 3, septiembre.

(1991), "Cultural Influences on Fertility and Family Planning in Peru", tesis de doctorado, Londres, Universidad de Londres.

Goldman, N., L. Moreno y C. Westoff (1989), Peru Experimental Study, and Evaluation of Fertility and Child Health Information, Columbia, Maryland, Office of Population Research, Princeton University, New Jersey and Institute for Resource Development/Macro Systems, Inc.

INE, Instituto Nacional de Estadística (1979), Encuesta Nacional de Fecundidad del Perú 1977-1978, Informe General, Lima.

(1983), Aspectos demográficos y prevalencia de anticonceptivos en el Perú 1981, Lima. (1986), Encuesta Nacional de Nutrición y Salud 1984, Informe General, Lima.

(1988), Encuesta Demográfica y de Salud Familiar (Endes 1986), Informe General, Lima.

Matos Mar, J., W. White y J. Cotler et al. (1969), Dominación y cambios en el Perú actual, Lima, Instituto de Estudios Peruanos.

Mercier, J.M. (1979), Nosotros los Napu-Runas/Napu Runapa Rimay, mitos e historia, Iquitos, Publicaciones CETA.

Nyrop, R.F. (ed.) (1981), Perú: A Country Study, Washington, D.C., Foreign Area Study, The American University.

Pontificia Universidad Católica del Perú (PUCP) (1971), Vida y cambioscultura asháninka, Informe de campo a la Comisión Intersectorial, Programa de Ciencias Sociales, Lima.

Regan, J. (1983), Hacia la tierra sin mal: Estudio de la religión del pueblo de la Amazonia, Iquitos, Centro de Estudios Teológicos de la Amazonia-CETA.

Rumrrill, R. (ed.) (1985), Iquitos: guía turística y cultural, Lima, Impresión Raúl Cano S.

Singh, S. y D. Wulf (1990), Tomorrow Parents: A Portrait of the Americas, Nueva York, Alan Guttmacher Institute. 
Varese, S. (1973), La sal de los cerros (una aproximación al mundo campa), Lima, Ediciones Retablo de Papel.

Vega Inca, G. (1609), Comentarios reales, Lima, Editorial Mercurio, 3 tomos (edición de 1986). 
